\title{
Revisiting nutrition-labor productivity link: new empirical evidence from farm households in Ethiopia
}

\author{
Andu Nesrey Berha ${ }^{1,3^{*}}$ (D) Yohannes Kefale Mogess ${ }^{2}$ and Mengistu Alamneh Wassie ${ }^{2}$
}

\begin{abstract}
Background: Among others, the productive use of surplus labor is a viable mechanism to transform the agricultural sector and thus the whole economy in low-income countries. It is critically important to understand the factors that condition labor productivity to design and deploy effective agricultural and labor market policies. A few studies confirm that, at low-income levels, improving nutrition can contribute to the labor productivity of households. These studies rely heavily on self-reported farm data, which are prone to systematic and random measurement errors. The empirical evidence on this topic remains inadequate and inconclusive for this reason. Here, we substantiate whether better nutritional status enhances the labor productivity of farm households using objective measures of plot-level data from a recent household survey in Ethiopia. We also employ alternative measures of nutrition status indicators known as, Food Consumption Score (FCS) and Household Dietary Diversity Score (HDDS), inter alia, to capture additional aspects of nutrition such as diet quality and diversity, which are overlooked by calorie intake data. To deal with possible endogeneity, we employ a panel fixed effect estimation technique with a rich set of household socioeconomic and plot characteristics.
\end{abstract}

Results: We observe that the impact of current nutritional status, as measured by HDDS, on labor productivity varies considerably depending on the initial level of diet quality and diversity with a stronger and positive effect for lowconsumption households. In an alternative specification, we also observe a positive farm labor productivity effect of current nutritional status as measured by FCS with a homogenous effect across households. However, the effect of the outcome of past nutritional status as evaluated by the Activity of Daily Living Index (ADLI) seems negligible.

Conclusion: Our findings indicate that improving nutrition can contribute to farm labor productivity at least for households with low current diet quality and diversity. Also, based on the findings, we conclude that there is a possibility of a low consumption-low productivity trap in Ethiopia.

Keywords: Labor productivity, Agriculture, Nutritional status, Measurement error, Fixed effect, Ethiopia

\section{Introduction}

Agriculture is the livelihood of more than 70 percent of the population in low-income countries [14]. Over the last two decades, most sub-Saharan African countries including Ethiopia have been putting tremendous effort

\footnotetext{
*Correspondence: s7anberh@uni-bonn.de; andunesrey@ddu.edu.et

${ }^{1}$ Dire Dawa University, P.O.Box: 1362, Dire Dawa, Ethiopia

Full list of author information is available at the end of the article
}

to transform the sector under Millennium Development Goals (MDGs) and Sustainable Development Goals (SDGs) frameworks. Such holistic development frameworks highly acknowledge the vital role of small-scale farms, which account for the lion's share of the sector. Among others, the productive use of surplus labor is a feasible mechanism to transform the agricultural sector and the whole economy too in low-income countries. It is critically important to look into the factors that condition 
farm labor productivity to design and deploy effective agricultural and labor market policies.

Micronutrient malnutrition and undernutrition are ubiquitous, however, the problem is more severe in subSaharan African countries. According to Global Nutrition Report, an average of $38.1 \%$ of women of reproductive age have anemia, and $8.1 \%$ of adult women have diabetes, compared to $7.9 \%$ of men while $17 \%$ of women and $7 \%$ of men have obesity. Malnutrition and undernutrition arise from a deficiency in the diet of iron and inadequate intake of energy and protein, respectively [26]. According to him, such nutritional predicaments reduce body size because of impaired growth and low oxygen-transporting capacity of the blood, thereby work capacity and intensity will deteriorate. In this circumstance, the relationship between poor nutritional status and low labor productivity could be a vicious circle and thus, the income inequality among rural poor is expected to be exacerbating.

The idea of the nutrition-labor productivity link has a long history; it is often known as the efficiency wage hypothesis. This hypothesis was introduced by Leibenstein [22] and has been widely studied and extended by subsequent researchers [4]. It stated that at low-income levels, better nutrition amplifies farm labor productivity as measured by wage and/or output, thereby foster economic growth [35]. A large body of empirical literature has attempted to test whether better nutrition enhances farm productivity in various occasions and settings (e.g., $[4,11,12,15,17,19,26,29,31,35,36])$. While some studies observed no positive productivity impact of nutrition, a large number of existing studies confirmed that nutrition has a significant and positive effect on household farm labor productivity.

Strauss [31] attempted to measure the response of family farm labor productivity to current nutritional status as measured by calorie intake in rural Sierra Leone. Using non-linear two-stage least squares (NL2SLS), he estimated the standard farm production function and finds a strong family farm labor productivity effect of calorie intake. However, the effect is very strong for the lowconsumption household. On the contrary, using panel data from south India, [12] reported that neither farm output nor earning respond to energy intake. However, he observed that the outcome of past nutritional status as measured by weight-for-height has a strong effect on the labor productivity of households in both wage equation and farm production function. Similarly, using a household survey from the southern Philippines, [15] estimated the wage equation, and they revealed that weight-for-height has a significant influence on farm labor productivity. However, they failed to confirm the significant influence of calorie intake on the farm labor productivity of households. On the other hand,
Traore [36] employed non-linear two-stage least squares (NL2SLS) and observes that calorie intake has a positive influence on the labor productivity of farm households in rural Malawi.

Recently Tiwasing et al. [35] found that unreliable access to a sufficient quantity of nutritious food leads to reduced work capacity and low productivity by examining the impact of micronutrient intake on the farm labor productivity of rice-producing households in Thailand. To address the possible simultaneity bias, they employed two-stage least squares (2SLS) and non-linear two-stage least squares (NL2SLS) methods to estimate a semi-log wage equation and Cobb-Douglas production function, respectively. Their results reveal that higher intakes of iron, calcium, and vitamin A can contribute to farm labor productivity measured by a household earning and farm output. However, they observed a negative labor productivity effect of calorie intake from the wage equation, which is surprisingly inconsistent with the nutritionproductivity hypothesis.

A few studies have also sought to document the nutrition-productivity link in Ethiopia (e.g., [4, 11, 19]). Croppenstedt and Muller [11] reported that both nutritional status and health have a positive influence on the farm productivity of rural households in Ethiopia. Similarly, using a rural household survey in Ethiopia, Ayalew [4] investigated the farm labor productivity effect of current and past nutritional status as measured by calorie intake and health, respectively. He estimated both production function and earning equation, and finds that calorie consumption has a positive effect on the family farm labor productivity of Ethiopian households. However, he observed the positive farm labor productivity effect of health only in the earning equation.

There is a lack of consensus among existing nutritionproductivity literature regarding the positive contribution of nutritional status to farm labor productivity of households. Besides, their inferences may likely be too far from reality owing to the following factors. First, until fairly recently, empirical agriculture literature has relied heavily on self-reported farm data. In such circumstances, the systematic and random measurement errors in output and farm inputs data are seemingly non-negligible [1], as often times, farmers report a rough estimate of actual yield level and plot size. For this reason, estimates of the productivity-nutrition model in existing studies may not be immune to biasedness and inconsistency.

Second, in the standard utility maximization model, the nutritional status indicators are choice variables that may be influenced by observable and unobservable household endowments that also influence output [12]. This is a common issue in nutrition productivity literature and should be addressed. Of course, some studies 
made efforts to address the endogeneity problem through exploiting exogenous sources of variation (i.e. instrumental variable approach) with a cross-sectional household survey. For instance, Tiwasing et al. [35] used the household size, operating month of data collection, region, and the number of a family member as instruments for the nutritional indicator, while Strauss [32] employed among others, hired labor calorie intake, output price index, and capital stock as instruments for nutrition status. On the other hand, Ayalew [4] used household demographics, mother and household head's education, and prices as instruments for health and current calorie intake. Notwithstanding, the output price index may not be a valid instrument, as farmers who reside in the same geographical region face fairly identical output prices in a given period, and thereby spatial price variation could be sparse. Hence, in order to observe adequate variation in price and obtain precise estimates, it is necessary to cover several regions or time series or both. Likewise, household characteristics in general, and household size, in particular, may not be valid instruments, give that those variables are under the control of the household at least in the long run. Moreover, some of the household characteristics (i.e. education and household size) can also have direct impacts on farm production and productivity.

Third, measuring the nutritional status of households is another challenge in nutrition-productivity literature. Despite most of the existing empirical studies have used average calorie intakes as a proxy of current nutritional status (e.g., $[4,12,31,35,40])$, measuring the calorie and energy contents of a set of foods items consumed by particular household members are subject to non-negligible measurement errors ([25] and [31]. Especially in developing countries context, this could be a series issue, given that most of the daily food items are locally producible, traditional, and specific to that particular area. Hence, existing inference of labor productivity impact of nutrition may not be immune to bias and inconsistency resulting from measurement flaws in calorie intake. Furthermore, caloric intake information addresses a question of quantity, however, it is quite silent regarding other complicated aspects of nutrition such as diet quality, diet diversity, and micronutrient sufficiency [24].

All the above concerns are serious and have to be addressed to obtain unbiased and consistent estimates of the nutrition-productivity model. To substantiate whether a better nutritional status promotes household farm labor productivity in Ethiopia, first, we make an effort to address the above identification threats explicitly. Last decade, the World Bank had conducted massive household and plot-level surveys in several developing countries including Ethiopia. Particularly, the Living Standard Measurement Study Integrated Surveys on
Agriculture (LSMS-ISA) is the most objective and thorough household survey in Ethiopia. It comprises both self-reported and crop-cut data for agricultural outputs. The cultivated plot sizes are measured using the Global Positioning System (GPS) tools in addition to holders' self-reported information. Also, the LSMS-ISA survey captures detail socioeconomic aspects of rural households and small towns. In this study, we use such a household survey, and by doing so we can at least reduce the possible bias resulting from measurement errors in self-reported farm output and input data.

Depending on the nature of available data, there are three practical approaches to circumvent possible endogeneity bias; panel estimation, instrumental variable approach, and randomized controlled experiment ${ }^{1}$ [30]. When the potential confounders are assumed to be timeinvariant, the panel fixed-effect is an ideal approach, whereas the instrumental variable approach is advisable in the case where the confounders are thought to be time-variant as well as unobservable [2]. To deal with possible endogeneity bias emanating from the endogenous nature of nutrition indicators, we use a panel fixed effect estimation technique so that we are able to control for time-invariant household-specific, plot-specific, and crop-specific confounders even though we are not in a position to control most of them. Besides, we control for available time-variant household and plot characteristics, as the omission of those controls can be another potential source of endogeneity in nutrition indicators. For this reason, our panel fixed effect estimates are assumed to be consistent and unbiased.

Finally, we try to lessen possible bias resulting from measurement error in nutritional status indicators, especially calorie intake. To do so, we employ alternative measures of nutritional status known as Food Consumption Score (FCS) and Household Dietary Diversity Score (HDDS), among others, (see more discussion in the data section). Therefore, this study aims to test whether a better nutritional status promotes family farm labor productivity using objective plot-level data and alternative measures of the current national status of rural households in Ethiopia.

Our findings can be a good addition to the nutritionalproductivity body of literature in the following dimensions. Unlike the previous studies, in this study, we use alternative nutritional status indicators and objective farm data to capture additional dimensions of nutrition and to reduce possible bias arising from measurement

\footnotetext{
${ }^{1}$ Despite the randomized control trial seems gold standard, it is less feasible in social science owing to, among others, ethical concerns and administrative cost [30].
} 
flaws, respectively. Hence, our findings can be further empirical evidence to the validity of the theoretical nutrition-labor productivity linkage. Moreover, our results can be an important input to the evidence-based propoor policymaking processes in Ethiopia and low-income countries too.

The remaining part of the paper is organized and proceed as follows. Following the introduction section, section two empirical strategy. Section three discusses the data source and nature. Section four and five are devoted to results and discussion altogether, and conclusion, respectively.

\section{Empirical strategy}

To estimate the effect of nutrition on labor productivity empirically, most nutrition-productivity literature use either a wage equation [15, 27, 34], Weinberner 2004; [19] or farm production function $[5,31,38]$ or both $([4,11$, $12,35]$ ). In such studies, the outcome variables (wage and farm output) measure labor productivity. In this article, we focus on only farm production function owing to the following factor. The nutrition-productivity hypothesis assumes that markets are functioning well and thus labor is paid its marginal product. However, this is not the case in low-income countries as input markets are highly imperfect. In some cases, the market does not even exist. The actual wage rate might not reflect the marginal product of the corresponding labor hour for this reason. In such a status quo, estimates of a wage equation may not help to test the empirical validity of the hypothesis.

Starting with a standard Cobb-Douglas farm production function ${ }^{2}$ :

$$
Y=f\left(L^{*}, L^{*}{ }_{h} L^{*}{ }_{s}, K, N, M\right),
$$

where $Y$ is output level, $L_{f}^{*}$ refers to effective family labor, $L^{*}{ }_{h}$ is effective hired labor, $L^{*}{ }_{s}$ indicates effective shared labor, $K$ is capital, $N$ represents cultivated land, and $M$ captures other intermediate inputs. ${ }^{3}$

Despite its inflexibility, the Cobb-Douglas production function has several appealing futures. For instance, its generalized form allows handling multiple inputs and different scales of production [42]. Moreover, CobbDouglas production function is seemingly good from a statistical point of view, one might expect little to be gained from a more complex structure (for example translog) unless the motivation underlying the research is a test of the maintained hypothesis embodied in the Cobb-Douglas production function [43].

\footnotetext{
${ }^{2}$ A number of existing studies use a Cobb-Douglas function (e.g., [4, 5, 12, 31, 35]).

${ }^{3}$ Fertilizer, seed, and pesticide.
}

Taking natural logarithmic on both sides of standard Cobb-Douglas function, then controlling for householdfixed effect and time-fixed effect, we have:

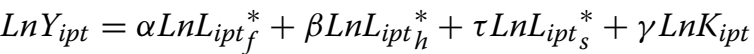

$$
\begin{aligned}
& +\delta L n N_{i p t}+\varphi L n M_{i p t}+\mu_{i}+\lambda_{t}+u_{i p t} .
\end{aligned}
$$

All available data on farm inputs and output are plot level, so $Y_{\text {ipt }}$ stands for farm output for household $i$, on plot $p$ and at time $t$, while $\mu_{i}$ is unobservable time-invariant household-fixed effects, $\lambda_{t}$ is year-fixed effects, ${ }^{4}$ and $u_{i p t}$ is a random error term. The omission of plot-specific factors may cause omitted variable bias [1], however, we make some effort to control for available plot characteristics. ${ }^{5}$

Following existing studies $[4,5,31,35]$ the effective family labor function is specified as:

$$
L_{i p t_{f}}^{*}=h\left(E\left(C_{i t a}, C_{i t n}\right)\right) * L_{i p t_{f}} .
$$

Effective family labor $\left(L_{i p t} t_{f}^{*}\right)$ in terms of efficient hours is a product of actual family labor input $\left(L_{i p t}\right)$ in clock hours and the efficiency per hour worked function, $h(.$.$) .$ The $h($.) function transforms a family labor clock hour into efficiency hour and is assumed to measure the productivity of the worker's effort [5]. $E\left(C_{i t_{a}}, C_{i t_{n}}\right)$ measures the current nutrition intake, which is a function of the flow of consumption of agriculture $\left(C_{i t a}\right)$ and non-agricultural $\left(C_{i t_{n}}\right)$ food items, ${ }^{6}$ for household $i$ at timet.

Even though the original specification of efficiency function does not capture past nutritional status or current health conditions, it is plausible to assume that the worker's productivity is likely affected by his/her health status in addition to current diet quality, diet diversity, and energy intake. Hence, following [4], [12], we extend the efficiency function in the following fashion:

$$
L_{i p t_{f}}^{*}=h\left(E\left(C_{i t a}, C_{i t n}\right), H_{i t}\right) * L_{i p t_{f}},
$$

where $H_{i t}$ indicates the outcome of past diet quality and diversity of farm household $i$ at time $t$ as measured by current health status or physical strength. Some studies confirm that past nutritional quality predicts current health status $[3,33]$.

Following early efficiency wage literature [6, 7], few existing studies put an effort to come up with S-shaped

\footnotetext{
${ }^{4}$ Year-specific effect captures inter alia, weather variations, and technological progress [28].

5 Soil quality and plot slop.

${ }^{6}$ Where $C_{a}$ and $C_{n}$ are the agricultural consumptions and non-agricultural consumption goods purchased from the market, while / indicates the leisure time.
} 
efficiency per hour worked function. ${ }^{7}$ However, many of the existing studies adopt different and flexible functional forms for the efficiency per hour worked function. Strauss [31] uses quadratic and log-reciprocal functions, while Ayalew [4] specifies the efficiency function differently, more resembles a Cobb-Douglas functional form. [12] also specifies the efficiency function in such a way $h($.$) is$ a function of a weighted average of daily energy intake of on-farm family workers and weighted average of weightfor-height with Cobb-Douglas functional form. In this study, we employ a Cobb-Douglas functional form following [12], hence, our main focus is only the concave portion of the prototype efficiency per hour worked function, as this part is a more relevant and observed economic region [31]:

$$
h\left(E\left(C_{i t a}, C_{i t n}\right), H_{i t}\right)=E_{i t}^{\rho} H_{i t}^{\vartheta} .
$$

Putting Eq. (5) into Eq. (4), we have:

$$
L_{i p t_{f}^{*}}^{*}=E_{i t}^{\rho} H_{i t}^{\vartheta} * L_{i p t},
$$

where $E_{i t}$ and $H_{i t}$ are the current nutritional intakes and outcome past nutritional quality, respectively.

To measure the outcome of past nutritional quality and diversity of the household, we use the Activities of Daily Living Index (ADLI). The index is assumed to pick up the medium-term nutritional status [4]. The score is computed based on six major health parameters (see Additional file 1: Appendix A).

Putting Eqs. (2) and (6) together, we have:

$$
\begin{aligned}
L n Y_{i p t}= & \alpha \rho L n E_{i t}+\alpha \vartheta \operatorname{LnH}_{i t}+\alpha L n L_{i p t} \\
& +\beta L n L_{i p t_{h}}+\tau L n L_{i p t_{s}}{ }^{*} \\
& +\gamma L n K_{i p t}+\delta L n N_{i p t}+\varphi L n M_{i p t} \\
& +\mu_{i}+\lambda_{t}+u_{i p t} .
\end{aligned}
$$

Following the same procedures, we can replace effective hired labor $\left(L_{i p t} t_{h}^{*}\right)$ and effective shared labor $\left(L_{i p t}{ }_{s}^{*}\right)$ by their respective clock hours labor and the efficiency per hour worked function. Notwithstanding, the model at hand captures only actual clock hour labor for hired and shard labor input as data on nutritional status of hired and shared labor are not available. Also, data on nutrition indicators are household level:

\footnotetext{
${ }^{7}$ Originally, $h($.) is hypothesized to have convex as well as concave portion. Initially, it increases at an increasing rate, thereafter increase at a decreasing rate (see [31],[4]. $\ln \left(\frac{L_{\text {Litf }}}{\text { Lint }_{\text {f }}}\right)=\rho \ln E_{i t}+\vartheta \ln H_{i t}$, where, $\rho$ and $\vartheta$ measure the elasticity efficiency units of labor with respect to current nutritional intake and past nutritional intake, respectively. Also, they are assumed to be less than unit.
}

$$
\begin{aligned}
L n Y_{i p t}= & \alpha \rho L n E_{i t}+\alpha \vartheta L n H_{i t}+\alpha L n L_{i p t_{f}}+\beta L n L_{i p t_{h}}+\tau L n L_{i p t_{s}} \\
& +\gamma L n K_{i p t}+\delta L n N_{i p t}+\varphi L n M_{i p t}+\mu_{i}+\lambda_{t}+u_{i p t} .
\end{aligned}
$$

\section{Data}

Over the last decade, the World Bank has conducted socioeconomic household surveys in several developing countries. Such an event creates an ample opportunity for agricultural researchers to revisit the existing body of literature. Especially, the Living Standard Measurement Study Integrated Surveys on Agriculture (LSMSISA) data are more objective relative to previous surveys, which are three waves of the longitudinal study, conducted by the World Bank in collaboration with the central Statistic Authority (CSA) of Ethiopia. The first and second waves were conducted in 2011/2012 and $2013 / 2014$, respectively. The third wave was surveyed in $2015 / 2016$. This survey has national coverage especially the second and third waves covered small and large towns including the capital city, Addis Ababa.

The survey is implemented based on a two-stage probability sampling. The first stage entailed the selection of primary sampling units or the CSA enumeration areas, EAs. Taking the size of the total EAs in each region into consideration, a total of 433 EAs are selected in a probability proportion. Then, to select representative sample households from each enumeration area of the most populous regions (Amhara, Oromia, SNNP, and Tigray), the quota is used. Finally, as a part of the effort to make the sample representative enough to the national households (i.e. rural, small, and large towns) and to ensure that all regions are well represented, the weighting of a sampling weight with a post-stratification adjustment is calculated. The survey was served in five major organized questionnaires. The household questionnaire was administered for the household in the sample. The community questionnaire was administered to a group of community members to collect information on the socioeconomic indicators of the enumeration areas where the sampled households reside. The next three agriculture questionnaires were administered to household members who engaged in agriculture activities. These are the postplanting, post-harvesting, and livestock questionnaires on different agriculture and asset-related variables.

Given the fragmented nature of the farming system in Ethiopia, information on farm inputs and outputs is plot level. Usually, each household has one or more plots and assigned each plot to a specific crop [1]. The cultivated plot sizes are measured using the Global Positioning System (GPS) tools in addition to holders' self-reported information. The LSMS-ISA survey also comprises both self-reported and crop-cut production data. The crop cut excesses were carried out on a 
limited number of plots. To undertake a crop-cut exercise, up to five plots are randomly selected in a given enumeration area per each of 23 crops. Once the plot selection is carried out, the crop cut exercise is performed on a limited portion ${ }^{8}$ of randomly selected plots. The total plot-level yield is extrapolated from the amount of yield harvested from the sub-plot, which is administered for crop cut operation. ${ }^{9}$ The LSMS-ISA survey also captures detail socioeconomic aspects of rural households and small towns.

In this article, we only use the plots which are measured using GPS as well as administered for crop cut practice owing to non-negligible measurement error in traditional self-reported plot size and output data. Even though the estimated crop cut harvest level and GPS-based measured plot size data are the most reliable farm data, they might also suffer from random and systematic measurement error owing to different factors. First, the characteristics of the sub-plot, which are randomly selected for crop cut exercise may not be representative enough to that particular plot with respect to soil quality and other plot characteristics. Second, the density of plot tree canopy cover and weather conditions at the time of measurement makes the GPS-based measured plot size prone to measurement error [10].

Table 1 presents the summary statistics of the farm inputs, farm outputs, past and current nutritional status indicators, and household and plot characteristics. As we can see from the table, on average household labor is the main source of farm labor input in rural Ethiopia as the mean of family labor is much larger than hired labor and shared labor. Similarly, from the 2013 Ethiopian Soil Experiment survey, we observe about $92.4 \%$ and $79.2 \%$ of the Ethiopian farmers use solely family labor during planting and harvest season, respectively.

The FCS is a composite score measure based on dietary diversity, food frequency, and relative nutrition of different food groups in a seven days' back consumption recall [39]. To construct the FCS for a given household, information on the consumption frequencies of each food item in the last past week before the survey is required. The household questionnaire in the LSMS-IS survey covers 16 food items. The food items are then sorted out into eight food groups ${ }^{10}$ as documented in [20]. Then

\footnotetext{
${ }^{8}$ The crop cut exercise is carried out on $2 \mathrm{~m}^{*} 2 \mathrm{~m}$ and $4 \mathrm{~m}^{*} 4 \mathrm{~m}$ of given plot size.

9 The crop cut manual is available at https://microdata.worldbank.org/ index.php/catalog/2053/download/40405.

10 According to WFP, the food groups are: staples (2), pulses (3), vegetables (1), fruit (1), meats, eggs, and fish (4), dairy products (4), sugars (0.5), and oils/fats (0.5). Figures with the brackets indicate the corresponding
}

Table 1 Summary statistics

\begin{tabular}{|c|c|c|c|}
\hline Variables & Mean & S.d & $N$ \\
\hline Amount of improved seed application (kg) & 4.218 & 13.59 & 5,415 \\
\hline Plot size measured using GPS (hectare) & 0.191 & 0.430 & 5,415 \\
\hline Irrigation dummy (irrigated =1) & 0.0222 & 0.147 & 5,415 \\
\hline $\begin{array}{l}\text { Total household labor used on the plot (person } \\
\text { days) }\end{array}$ & 11.69 & 14.72 & 5,415 \\
\hline Total hired labor used on the plot (person days) & 4.286 & 73.85 & 5,415 \\
\hline $\begin{array}{l}\text { Total labor used from other households (person } \\
\text { days) }\end{array}$ & 1.650 & 6.741 & 5,415 \\
\hline Household size & 5.747 & 2.199 & 5,415 \\
\hline Age of the household head & 49.00 & 14.31 & 5,415 \\
\hline Number of crops & 1.119 & 0.415 & 5,415 \\
\hline Number of plots & 2.449 & 2.629 & 5,415 \\
\hline Soil quality dummy ${ }^{\mathrm{a}}(\operatorname{good}=1)$ & 0.209 & 0.407 & 5,415 \\
\hline Crop cut production (quintals) & 2.499 & 8.898 & 5,415 \\
\hline Total fertilizer application (kg) & 7.579 & 26.21 & 5,415 \\
\hline PSNP participation dummy ${ }^{b}$ participated $=1$ ) & 0.955 & 0.207 & 5,415 \\
\hline Crop rotation dummy (yes $=1$ ) & 0.117 & 0.322 & 5,415 \\
\hline Extension service dummy (received $=1$ ) & 0.508 & 0.500 & 5,415 \\
\hline Advisory service dummy (received $=1$ ) & 0.229 & 0.420 & 5,415 \\
\hline Household dietary diversity score & 4.578 & 1.439 & 5,415 \\
\hline Health $(A D L I)^{c}$ & 0.989 & 0.0289 & 5,415 \\
\hline Food consumption score & 43.82 & 16.59 & 5,415 \\
\hline Number of clusters & & & 1,739 \\
\hline
\end{tabular}

Author calculation. See Additional file 1: Appendix A for the description of the variables

${ }^{a}$ We assume that the soil quality is changing across time owing to erosion and nitrogen leaching

${ }^{\mathrm{b}}$ The Productive Safety Net Programme (PSNP) is a welfare improvement program by the Government of Ethiopia to the food-insecure households. The household exposure to the program changes across time

'See Additional file 1: Appendix A for detailed information about the Activity of Daily Living Index and a full description of all variables

the consumption frequencies of food items of the same group are summed, and the food group with consumption frequencies of more than seven counted as seven. To compute the score per food group, each food group is multiplied by the corresponding FCS weight. Finally, the Food Consumption Score (FCS) for each observation is obtained by adding up the weighted group-level scores.

The Household Dietary Diversity Score (HDDS) is also an indicator of diet quality and diversity according to the Food and Agriculture Organization (FAO), and

\section{Footnote 10 (continued)}

weight, and all available condiments are taking zero weight. The World Food Program proposes the thresholds for FCS with 112 as a maximum possible score, which are: $0-21$ : poor; $21.5-35$ : borderline; $>35$ : acceptable, while International Food Policy Research Institute-IFPRI uses the following thresholds for HDDS: 4 4.5: low dietary diversity; 4.5-6: medium dietary diversity; $6+$ : high dietary diversity. More information is available at https://inddex.nutrition.tufts.edu/data4diets/indicator/food-consumptionscore-fcss. 
the International Food Policy Research Institute (IFPRI). It exploits a flexible consumption recall period ranging from 24-h up to 7 days. To calculate HDDS, we use the eight food groups following Hidrobo et al. (2013), however, some studies use 12 food groups. Unlike the FCS setting, in HDDS, each food group and food item takes the value of either one or zero. If the household consumes a particular food group within the recall period, it is recorded as one, otherwise, zero. Finally, the HDDS is obtained by taking the summation of binary values from eight food groups. ${ }^{11}$

The FCS and HDDS have a high association ${ }^{12}$ and are used as a validated proxy for household-level diet diversity and quality, and energy sufficiency in most circumstances [24]. To check the validity of HDDS and FCS consumption recall-based methods, we estimate correlation coefficients between FCS and HDDS against household income. We find a positive and strong association between HDDS and FCS against household income at a $10 \%$ level of significance. The FCS is being used widely by World Food Program-WFP in their surveillance activities while HDDS was first used by the FAO and WFP as well. Food Consumption Score and Household Dietary Diversity Score are attractive qualitative measures of nutrition status as they require less information and time to construct them relative to quantitative dietary intake methods [20], thus, they are expected to be less prone to the measurement error. More importantly, FCS and HDDS capture the key notions of nutrition such as diet quality and diversity which are overlook by calorie intake [24]. However, FCS and HDDS have their limitation. FCS and HDDS don't show the proportion of household food utilization insecurity [37], and are not sensitive to intrahousehold inequities in food consumption [18]. Thus, FCS and HDDS should not be used for interventions specifically targeting individuals, such as nutritionally vulnerable women or children [18].

\section{Empirical results and discussion Estimation of farm production function}

Tables 2 and 3 show panel fixed effect estimates of CobbDouglas farm production function under different specifications and set of controls. The first column in Table 2 shows the estimated results of baseline specification, in which the current nutritional status is measured by the Household Dietary Diversity Index (HHDS) and its square. In such a particular specification, we control for a limited number of control variables, which are suggested

\footnotetext{
${ }^{11}$ The maximum possible score that the HDDS takes is 8 .

12 We observe 0.71 correlation between FCS and HDDS with p-value 0.0000 .
}

Table 2 Panel fixed effect estimates of the Cobb-Douglas farm production function

\begin{tabular}{|c|c|c|c|}
\hline Independent variables & (I) & (II) & (III) \\
\hline \multirow[t]{2}{*}{ Household dietary diversity score } & $0.390^{*}$ & $0.394^{*}$ & $0.408^{*}$ \\
\hline & $(0.211)$ & $(0.212)$ & $(0.218)$ \\
\hline \multirow{2}{*}{$\begin{array}{l}\text { Household dietary diversity score } \\
\text { squared }\end{array}$} & $-0.128^{*}$ & $-0.128^{*}$ & $-0.131^{*}$ \\
\hline & $(0.0703)$ & $(0.0706)$ & $(0.0724)$ \\
\hline \multirow[t]{2}{*}{ Health (ADLI) } & 0.235 & 0.380 & 0.395 \\
\hline & $(0.947)$ & $(0.945)$ & $(0.910)$ \\
\hline \multirow[t]{2}{*}{ Measured land } & $2.974 * * *$ & $2.968^{* * *}$ & $2.973^{* * *}$ \\
\hline & $(0.173)$ & $(0.173)$ & $(0.174)$ \\
\hline \multirow[t]{2}{*}{ Household labor (person days) } & $0.0565^{* * *}$ & $0.0567^{* * *}$ & $0.0574^{* * *}$ \\
\hline & $(0.0108)$ & $(0.0109)$ & $(0.0108)$ \\
\hline \multirow[t]{2}{*}{ Hired labor (person days) } & 0.0123 & 0.0120 & 0.0106 \\
\hline & $(0.0151)$ & $(0.0152)$ & $(0.0151)$ \\
\hline \multirow[t]{2}{*}{ Shared labor (person day) } & $0.0539^{* * *}$ & $0.0517^{* * *}$ & $0.0513^{* * *}$ \\
\hline & $(0.0126)$ & $(0.0129)$ & $(0.0129)$ \\
\hline \multirow[t]{2}{*}{ Fertilizer in $\mathrm{kg}$} & $0.0691^{* * *}$ & $0.0689^{* * *}$ & $0.0694^{* * *}$ \\
\hline & $(0.00876)$ & $(0.00877)$ & $(0.00887)$ \\
\hline \multirow[t]{2}{*}{ Improved seed in kg } & 0.0222 & 0.0225 & 0.0213 \\
\hline & $(0.0151)$ & $(0.0154)$ & $(0.0153)$ \\
\hline \multirow[t]{2}{*}{ Number of plots } & & -0.0106 & -0.0118 \\
\hline & & $(0.0153)$ & $(0.0154)$ \\
\hline \multirow[t]{2}{*}{ Head age } & & 0.0468 & 0.0283 \\
\hline & & $(0.137)$ & $(0.136)$ \\
\hline \multirow[t]{2}{*}{ Household size } & & -0.0644 & -0.0609 \\
\hline & & $(0.0682)$ & $(0.0690)$ \\
\hline \multirow[t]{2}{*}{ Number of crops } & & 0.0371 & 0.0365 \\
\hline & & $(0.0631)$ & $(0.0626)$ \\
\hline \multirow[t]{2}{*}{ Irrigation dummy } & & & 0.0230 \\
\hline & & & $(0.0824)$ \\
\hline \multirow[t]{2}{*}{ Soil quality dummy } & & & 0.0189 \\
\hline & & & $(0.0252)$ \\
\hline \multirow[t]{2}{*}{ PSNP dummy } & & & 0.0202 \\
\hline & & & $(0.0659)$ \\
\hline \multirow[t]{2}{*}{ Crop rotation dummy } & & & $0.114^{* *}$ \\
\hline & & & $(0.0497)$ \\
\hline \multirow[t]{2}{*}{ Extension dummy } & & & 0.000682 \\
\hline & & & $(0.0308)$ \\
\hline \multirow[t]{2}{*}{ Advisory dummy } & & & 0.0449 \\
\hline & & & $(0.0355)$ \\
\hline Household FE & Yes & Yes & Yes \\
\hline Year FE & Yes & Yes & Yes \\
\hline Crop FE & Yes & Yes & Yes \\
\hline Observations & 5,415 & 5,415 & 5,415 \\
\hline R-squared & 0.624 & 0.624 & 0.626 \\
\hline Number of cluster & 1,739 & 1,739 & 1,739 \\
\hline
\end{tabular}

The dependent variable is the crop-cut harvest volume measured in quintal. The standard errors in parenthesis are clustered at the household level. The current nutrition status indicator is Household Dietary Diversity Score (HDDS) and its square. All variables, except dummy controls, are in natural logarithmic form so that the coefficients can be interpreted as elasticity. ${ }^{* * *} p<0.01,{ }^{* *} p<0.05$, ${ }^{*} p<0.1$ 
Table 3 Panel fixed effect estimates of the Cobb-Douglas farm production function

\begin{tabular}{|c|c|c|c|}
\hline Independent variables & (I) & (II) & (III) \\
\hline \multirow[t]{2}{*}{ Food consumption score } & $0.160^{*}$ & $0.159^{*}$ & $0.187^{* *}$ \\
\hline & $(0.0881)$ & $(0.0887)$ & $(0.0926)$ \\
\hline \multirow[t]{2}{*}{ Food consumption score squared } & -0.0177 & -0.0170 & -0.0210 \\
\hline & $(0.0156)$ & $(0.0157)$ & $(0.0161)$ \\
\hline \multirow[t]{2}{*}{ Health (ADLI) } & 0.249 & 0.401 & 0.414 \\
\hline & $(0.940)$ & $(0.937)$ & $(0.903)$ \\
\hline \multirow[t]{2}{*}{ Measured land } & $2.974^{* * *}$ & $2.968^{* * *}$ & $2.972^{* * *}$ \\
\hline & $(0.173)$ & $(0.173)$ & $(0.174)$ \\
\hline \multirow[t]{2}{*}{ Household labor (person days) } & $0.0564^{* * *}$ & $0.0566^{* * *}$ & $0.0573^{* * *}$ \\
\hline & $(0.0108)$ & $(0.0109)$ & $(0.0109)$ \\
\hline \multirow[t]{2}{*}{ Hired labor (person days) } & 0.0126 & 0.0123 & 0.0108 \\
\hline & $(0.0151)$ & $(0.0153)$ & $(0.0151)$ \\
\hline \multirow[t]{2}{*}{ Shared labor (person days) } & $0.0538^{* * *}$ & $0.0515^{* * *}$ & $0.0511^{* * *}$ \\
\hline & $(0.0126)$ & $(0.0129)$ & $(0.0129)$ \\
\hline \multirow[t]{2}{*}{ Fertilizer in kg } & $0.0692^{* * *}$ & $0.0691^{* * *}$ & $0.0696^{* * *}$ \\
\hline & $(0.00876)$ & $(0.00878)$ & $(0.00888)$ \\
\hline \multirow[t]{2}{*}{ Improved seed in kg } & 0.0231 & 0.0234 & 0.0222 \\
\hline & $(0.0151)$ & $(0.0154)$ & $(0.0154)$ \\
\hline \multirow[t]{2}{*}{ Number of plots } & & -0.0131 & -0.0140 \\
\hline & & $(0.0153)$ & $(0.0154)$ \\
\hline \multirow[t]{2}{*}{ Head age } & & 0.0461 & 0.0258 \\
\hline & & $(0.138)$ & $(0.136)$ \\
\hline \multirow[t]{2}{*}{ Household size } & & -0.0686 & -0.0650 \\
\hline & & $(0.0686)$ & $(0.0694)$ \\
\hline \multirow[t]{2}{*}{ Number of crops } & & 0.0386 & 0.0382 \\
\hline & & $(0.0635)$ & $(0.0629)$ \\
\hline \multirow[t]{2}{*}{ Irrigation dummy } & & & 0.0247 \\
\hline & & & $(0.0825)$ \\
\hline \multirow[t]{2}{*}{ Soil quality dummy } & & & 0.0169 \\
\hline & & & $(0.0252)$ \\
\hline \multirow[t]{2}{*}{ PSNP dummy } & & & 0.0278 \\
\hline & & & $(0.0660)$ \\
\hline \multirow[t]{2}{*}{ Crop rotation dummy } & & & $0.116^{* *}$ \\
\hline & & & $(0.0502)$ \\
\hline \multirow[t]{2}{*}{ Extension dummy } & & & 0.00340 \\
\hline & & & (0.0309) \\
\hline \multirow[t]{2}{*}{ Advisory dummy } & & & 0.0462 \\
\hline & & & $(0.0356)$ \\
\hline Household FE & Yes & Yes & Yes \\
\hline Year FE & Yes & Yes & Yes \\
\hline Crop FE & Yes & Yes & Yes \\
\hline Observations & 5,415 & 5,415 & 5,415 \\
\hline R-squared & 0.624 & 0.625 & 0.626 \\
\hline Number of clusters & 1,739 & 1,739 & 1,739 \\
\hline
\end{tabular}

The dependent variable is crop-cut harvest volume measured in quintal. The standard errors in parenthesis are clustered the household level. The current nutritional status indicator is the Food Consumption Score (FCS) and its square. All variables, except dummy controls, are in natural logarithmic form so that the coefficients can be interpreted as elasticity. ${ }^{* * *} p<0.01,{ }^{* *} p<0.05,{ }^{*} p<0.1$ by the underlying farm production function. Column two in the same table also shows panel fixed effect estimates of farm production function after controlling for additional continuous controls (i.e. household age, number of crops, household size, and number of plots) in addition to controls in the baseline model. The final column also presents the estimates of the farm production function, which captures the available binary household and plot characteristics in addition to continuous controls in column two. Our analyses mostly rely on the 3rd column, given that in such particular specification we make an effort to control for available time-variant household and plot characteristics, hence the specification is assumed to be robust to omitted variable bias or possible endogeneity threat. Across all specifications, we control for household-fixed effect, crop-fixed effect, and time-fixed effect.

Some important features are evident from Table 2. Consistent with the nutrition-productivity hypothesis, the current nutritional status as measured by HDDS and its square has a statistically significant impact on farm labor productivity as measured by output under all three specifications. The household labor productivity increases with current nutritional status up to a point in each specification. The most interesting point here is that the magnitudes and significances of the coefficients on HDDS and its square are less sensitive to controlling for additional covariates in columns two and three. Of course, the inclusion of additional controls in columns two and three results in some improvement in the magnitude of the coefficients, but the change is very gentle, while the significances remain the same across all specifications. It is not surprising to observe a negative coefficient of HDDS squared, it implies that the labor productivity effect of current nutritional status varies among households with stronger and positive effect for low-consumption household, which is in line with almost all existing studies $[4,31]$, among others.

The outcome of past nutritional status (or current health condition) measured by ADLI is found to have a statistically insignificant impact on farm productivity in all specifications. It is possible to argue that the insignificant effect of ADLI can be due to the HDDS and its square probably pick up the medium-term effect of nutrition in addition to the immediate effect, given that the correlation between those nutrition indicators is statistically significant and positive. To justify such a claim, we re-estimate all three models without HDDS as well as its square. We find some improvements in the magnitude and significance of the coefficient of ADLI under all specifications (not reported here). Another possible explanation is that the data on ADLI may not immune to systematic and random measurement errors as it is 
extremely relaying on self-reported ${ }^{13}$ health status. In most cases, the measurement errors result in downward bias.

Consistent with the existing theory and empirics, the coefficient on each major farm input, except hired labor and improved seed, is highly significant and positive. The labor productivity effect of the measured cultivated plot is quite high, whereas the coefficients of household labor and shared labor are moderate and fairly close across all specifications. On the other hand, the coefficient of hired labor is statistically insignificant, which is consistent with Strauss [31]. Despite existing studies argue that technology adoption is imperative to enhance agricultural productivity, our estimate reveals that the improved seed has a statistically insignificant impact on production. However, the effect of fertilizer seems highly significant and positive.

The coefficients of additional continuous control variables (i.e. number of plots, household age, family size, and a number of crops) are found to have statistically insignificant. Moreover, except for crop rotation, the coefficient of each categorical dummy household and plot characteristic is not significantly different from zero. Even though the coefficients on those additional controls are statistically insignificant, the inclusion of such controls brings a little improvement on coefficients of the nutritional status indicators. It implies that there is a possibility of a downward bias on the coefficients of the HDDS and its square in the case where those controls are omitted from the farm model as the coefficients of the HDDS and its square are a bit smaller in column one.

Table 3 also presents the panel fixed effect estimates of the farm production function, in which the Food Consumption Score (FCS) and its square represent current nutritional status, but the regression is the same as Table 2. Under all specifications, the productivity effect of current nutrition status seems positive and the same across all households. The coefficient of FCS appears highly significant in the third specification; however, its square is surprisingly found to have insignificant under all specifications. The measurement issue in FCS may be a possible reason for the negligible effect of FCS squared. As the part measurement guideline documented in the World Food program's official document, a food group with consumption frequencies of more than seven within the recall period must be counted as seven [41]. Such restriction likely restrains and understates the possible variation in current nutritional status among households

\footnotetext{
${ }^{13}$ The respondent is asked to rate his/her health status in one of the given categories, hence the metric is more arbitrary and subjective as well. Also, the term "good health" might not be the same thing for all individuals (Strauss, 1998).
}

with a high level of Food Consumption Score. To confirm such a claim, we compute the FCS without such restriction and re-estimate the third specification. We observe that the coefficients of FCS and its square are statistically significant at 0.1 level (not reported here).

Furthermore, as the Household Dietary Diversity Index (HDDS) is found to have a non-linear effect on productivity, one can argue that the effect can be deteriorating once the HDDS passes a certain threshold point. Considering this, we make an effort to estimate the average threshold at which the effect of HDDS is zero. The effect of HDDS on labor productivity is positive up to a value of $1.5 \mathrm{log}$ HDDS. The impact of HDDS on labor productivity gets negative when log HDDS passes a given threshold. More disaggregated results are presented in Additional file 1: Appendix B. ${ }^{14}$

\section{Elasticities and marginal products}

Table 4 depicts elasticities of output with respect to each major farm input and nutritional status indicator, and their marginal products on the left and right column, respectively. ${ }^{15}$ The magnitude of the elasticity of farm output with respect to HDDS seems low at the sample mean. However, the magnitude considerably varies with the initial level of the current nutritional status indicator with a stronger effect for low-consumption households. When the HDDS falls between 1 and 2, the elasticity of output ranges from 0.408 to 0.225 , whereas it drops to zero at 4.7 HDDS. Consistent with Strauss [31], the farm output is highly responsive to a percent change in measured cultivated plot size compared to other fixed and intermediate farm inputs. Moreover, contradicting Ayalew's [4] finding, the elasticity of fertilizer is much larger than the current nutritional indicator. In his study, Ayalew confirms that the elasticity of output with respect to current nutritional status (i.e. calorie intake) is much large than major agricultural inputs, like fertilizer application and labor input. ${ }^{16}$

In line with previous studies [5, 31], we observe the largest marginal product of cultivated plot size at the sample mean. The marginal products of current

\footnotetext{
${ }^{14}$ We made an effort to disaggregate our findings by the gender of the household head. The results suggest that the impact of nutrition (as measured by HDDS and FCS) on farm labor productivity is positive for both groups but the result seems insignificant for the female head. This can be aroused due to the fact the disaggregation by gender results in a disproportionate partition. Out of the total sample, $85 \%$ are male (See Additional file 1: Appendix B).

15 The estimates of elasticities and marginal products are based on 3rd column of Table 2 and 3.

16 According to Ayalew [4], even the combined effect of chemical fertilizers, hoe, and plow is far lower than the calorie intake, which is assumed to measure current nutritional status.
} 
Table 4 Farm output elasticities and marginal products at sample mean

\begin{tabular}{lll}
\hline Independent variables & Output elasticity & Marginal product \\
\hline $\begin{array}{l}\text { Household dietary diversity } \\
\text { score }\end{array}$ & 0.00778 & 0.0043 \\
Food consumption score & 0.0276 & 0.0016 \\
Health (ADLI) & 0.383 & 0.9677 \\
Measured land & 2.974 & 38.9111 \\
Household labor & 0.0574 & 0.0123 \\
Hired labor & 0.0107 & 0.0062 \\
Shared labor (person day) & 0.0514 & 0.0778 \\
Fertilizer in kg & 0.0693 & 0.0229 \\
Improved Seed in kg & 0.0213 & 0.0126 \\
$N$ & 5415 & 5415 \\
\hline
\end{tabular}

Elasticities and marginal productivities are computed at the sample mean. The elasticities on Food Consumption Score, Health (ADLI), Hired Labor, and Improved Seed are statistically insignificant

nutritional indicators seem low in contrast to other major farm inputs. Moreover, the marginal productivities of the household labor and improved seed look quite close, and the marginal product of hired labor appears relatively low.

\section{Conclusion}

In this study, we try to look into the impact of nutritional status on family farm labor productivity using Living Standard Measurement Study Integrated Surveys on Agriculture (LSMS-ISA) data for Ethiopia. As a part of our effort to come up with further plausible evidence about the theoretical nutrition-productivity linkage, we try to address the measurement error in farm inputs, output, and nutritional status indicators data explicitly, which is a series identification threat in existing studies. Besides, we employ alternative measures of nutrition status known as Food Consumption Score (FCS) and Household Dietary Diversity Score (HDDS) to capture important aspects of nutrition such as diet quality and diversity, which are overlooked by calorie intake data. In this study, such consumption recall-based methods are thought to measure the current nutritional status of the household. Moreover, following existing studies, Activity Daily Living Index (ADLI) is employed to measure the outcome of past nutritional intake or the health status of rural households. We also make an effort to deal with possible bias resulting from the endogenous nature of nutritional status indicators.

Under three different scenarios, the standard CobbDouglas farm production function is estimated using a panel fixed effect estimation technique for each of the current nutritional status indicators. In the baseline specification, we control for only major farm production function inputs in addition to nutrition indicators. In the second and third specifications, we control for additional continuous covariates, and dummy household and plot characteristics, respectively. Also, all specifications are conditional on crop-fixed effect, time-fixed effect, and household-fixed effect.

The estimated elasticities show that the current nutritional status indicator as measured by HDDS and its square has a statistically significant effect on household farm labor productivity as measured by farm output, however, the effect varies depending on the initial level of nutritional status with a stronger and positive effect for low-consumption households, and it seems deteriorating with diet quality and diversity improvement. The estimates of the alternative model also show that the current nutritional status as measured by FCS and its square has a positive and linear effect on the labor productivity of farm households. Despite we observe the negligible effect of the outcome of past nutritional status as measured by ADLI, our findings indicate that improving nutrition can contribute to household labor productivity at least for households with low current diet quality and diversity status. Hence, our findings firmly support the nutritionproductivity hypothesis. Moreover, based on the findings, we can infer that there is a possibility of a low consumption-low productivity trap in Ethiopia as documented in Ayalew [4]. What the results do imply for policy design is that to enhance farm labor productivity and thereby economic growth, the governments and other concerned bodies in low-income countries should pay considerable attention to the problem of malnutrition and undernourishment through adopting effective social protection and welfare programs. This policy direction can also be an effective way to lessen the excessive income inequality among households.

We also observe that all major farm inputs, except hired labor and improved seed, have a highly significant and positive influence on the labor productivity of farm households, and the magnitude of the coefficient of cultivated land appears largest. Thus, policymakers in developing countries should implement and deploy a proper land distribution policy to transform the sector. Moreover, the government in low-income countries should also work a lot on modern farm inputs availability through subsidizing high-cost inputs, especially chemical fertilizer in addition to improving the nutritional status of the deprived farm households directly.

Even though the study at hand provides new empirical insight on the nutrition labor productivity link of farm households in Ethiopia, there are a few limitations that 
are observed and anticipated on it. First, even though we control for several household socioeconomic characteristics, a panel fixed effect estimation technique cannot help to deal with a biasedness that arises from the omission of time-variant unobservable confounders. Second, even though consumption recall-based methods, such as Household Dietary Diversity Score (HDDS) and Food Consumption Score (FCS) provide adequate information regarding household nutrition status, they may not help to explore intra-household nutrition status variation. Also, consumption recall-based methods are subject to random and systematic measurement errors due to the fact that food consumption survey relies on self-reported data. Finally, owing to data limitation, this study has not taken into account some sort of modern or traditional mechanization that could help to improve labor productivity. These concerns should be scope for future studies.

\begin{abstract}
Abbreviations
2SLS: Two-stage least square; ADLI: Activity Daily Living Index; CSA: Central Statistical Agency; FAO: Food and Agriculture Organization; FCS: Food Consumption Score; GNR: Global Nutrition Report; GPS: Global Positioning System; HDDS: Household Dietary Diversity Score; IFPRI: International Food Policy Research Institute; LSMS-ISA: Living Standard Measurement Study Integrated Surveys on Agriculture (LSMS-ISA); MDGs: Millennium Development Goals; NL2SLS: Non-linear two-stage least square; PSNP: The Productive Safety Net Programme; SDGs: Sustainable Development Goals; SNNP: Southern Nations, Nationalities, and Peoples'; WFP: World Food Program.
\end{abstract}

\section{Supplementary Information}

The online version contains supplementary material available at https://doi. org/10.1186/s40066-021-00312-x.

Additional file 1: Appendix A: Table A1. Food group and standardized food weight. Source: INDDEX Project (2018). Table A2. Variables description. Source: LSMS-ISA data. Appendix B: Table B1. Panel Fixed Effect Estimates of the Cobb-Douglas farm production function for male head. Source: Authors calculation based on LSMS-ISA data. Table B2. Panel Fixed-effect estimates of the Cobb-Douglas farm production function for female head. Source: Authors calculation based on LSMS-ISA data. Table B3. Panel Fixed-effect estimates of the Cobb-Douglas farm production function without restriction. Source: Authors calculation based on LSMS-ISA data. Appendix C: Figure C1. Local Polynomial Regression. Source: Authors calculation based on LSMS-ISA data. Figure C2. Distribution of variables. Source: Authors calculation based on LSMS-ISA data.

\section{Acknowledgements}

Not applicable.

\section{Authors' contributions}

The research idea was originally thought by ANB. The authors searched for the existing literature together. They equally contributed together in specifying the empirical models and analyzing the econometric results. They also discussed the results, wrote up the manuscript, and revised the paper. All authors read and approved the final manuscript.

\section{Funding}

This research did not receive any specific grant from funding agencies in the public, commercial, or not-for-profit sectors.
Availability of data and materials

The datasets and Stata do-files are available from the corresponding author upon reasonable request.

\section{Declarations}

Ethics approval and consent to participate

Not applicable.

\section{Consent for publications}

The authors confirm that the content of the manuscript has not been published, or submitted for publication elsewhere.

\section{Competing interests}

The author(s) declared no potential competing interest with respect to the research, authorship, and/or publication of this article.

\section{Author details}

'Dire Dawa University, P.O.Box: 1362, Dire Dawa, Ethiopia. ${ }^{2}$ Haramaya University, P.O.Box 138, Dire Dawa, Ethiopia. ${ }^{3}$ University of Bonn, 53115 Bonn, Germany.

Received: 20 October 2020 Accepted: 1 June 2021

Published online: 28 October 2021

\section{References}

1. Abay KA, Abate GT, Barrett CB, Bernard T. Correlated non-classical measurement errors, 'Second best policy inference, and the inverse sizeproductivity relationship in agriculture. J Dev Econ. 2019;139:171-84.

2. Angrist JD, Pischke JS. Mostly harmless econometrics: An empiricist's companion. Princeton university press; 2008.

3. Asenso-Okyere K, Chiang C, Thangata P, Mekonnen DA. Understanding the interaction between farm labor productivity, and health and nutrition: A survey of the evidence. J Dev Agric Econ. 2011;3(3):80-90.

4. Ayalew T. Nutrition-productivity link and the persistence of poverty. Institute of Development Policy (IOB): Universiteit Antwerpen; 2003.

5. Aziz F. Nutrition, health and labor productivity analysis of male and female workers: a test of the efficiency wage hypothesis; 1995.

6. Bliss C, Stern N. Productivity, wages and nutrition: Part I: the theory. J Dev Econ. 1978;5(4):331-62.

7. Bliss C, Stern N. Productivity, wages and nutrition: Part II: Some observations. J Dev Econ. 1978;5(4):363-98.

8. Cameron AC, Trivedi PK. Microeconometrics: methods and applications. Cambridge university press; 2005.

9. Campelo GL, De-França JMS, Marinho ELL. Impacts of malnutrition on labor productivity: empirical evidences in rural Brazil. Anais do XLII Encontro Nac. de Econ.[Proce. 42ndd Braz. Econ. Meet.], (236); 2016.

10. Carletto C, Savastano S, Zezza A. Fact or artifact: The impact of measurement errors on the farm size-productivity relationship. J Dev Econ. 2013;103:254-61.

11. Croppenstedt A, Muller C. The impact of farmers' health and nutritional status on their productivity and efficiency: Evidence from Ethiopia. Econ Dev Cult Change. 2000;48(3):475-502.

12. Deolalikar AB. Nutrition and labor productivity in agriculture: estimates for rural South India. The review of Economics and Statistics. 1988; 406-13.

13. Dhrymes PJ. Topics in advanced econometrics: Volume II linear and nonlinear simultaneous equations. Springer Science \& Business Media; 2012.

14. Gourlay S, Kilic T, Lobell D. Could the debate be over? errors in farmerreported production and their implications for the inverse scale-productivity relationship in Uganda. The World Bank; 2017.

15. Haddad L, Bouis HE. The impact of nutritional status on agricultural productivity: wage evidence from the Philippines. 1989.

16. Hidrobo M, Hoddinott J, Peterman A, Margolies A, Moreira V. Cash, food, or vouchers? Evidence from a randomized experiment in northern Ecuador. J Dev Econ. 2014;107:144-56. 
17. Immink MD, Viteri FE. Energy intake and productivity of Guatemalan sugarcane cutters: An empirical test of the efficiency wage hypothesis part I. journal of Development Economics. 1981. 9(2):251-71.

18. INDDEX Project Data4Diets. Building Blocks for Diet-related Food Security Analysis. Tufts University, Boston, MA 2018. https://inddex.nutrition.tufts. edu/data4diets

19. Kedir AM. Health and wages: Panel evidence on men and women using IV Quantile Regression. Discussion Papers in Economics. 2008;8:37.

20. Kennedy G, Berardo A, Papavero C, Horjus P, Ballard T, Dop M, Delbaere J, Brouwer ID. Proxy measures of household food consumption for food security assessment and surveillance: comparison of the household dietary diversity and food consumption scores. Public health nutrition. 2010;13(12)

21. Kirk A, Kilic T, Carletto C. Composition of household income and child nutrition outcomes evidence from Uganda. World Dev. 2018;109:452-69.

22. Leibenstein H. Economic backwardness and economic growth. 1957.

23. Levine R, Zervos SJ. What we have learned about policy and growth from cross-country regressions? Am Econ Rev. 1993;83(2):426-30.

24. Maxwell D, Coates J, Vaitla B. How do different indicators of household food security compare? Empirical evidence from Tigray. Medford: Tufts University; 2013. p. 26.

25. Pérez-Escamilla R, Segall-Corrêa AM. Food insecurity measurement and indicators. Rev Nutr. 2008;21:15s-26s.

26. Popkin BM. Nutrition and labor productivity. Social Science \& Medicine. Part C: Medical Economics. 1978;12(1-2):117-25.

27. Sahn DE, Alderman $H$. The effects of human capital on wages, and the determinants of labor supply in a developing country. J Dev Econ. 1988;29(2):157-83.

28. Sheng Y, Ding J, Huang J. The relationship between farm size and productivity in agriculture: Evidence from maize production in northern China. Am J Agr Econ. 2019;101(3):790-806.

29. Spurr GB. Nutritional status and physical work capacity. Am J Phys Anthropol. 1983;26(S1):1-35

30. Stock, James H., and Mark W. Watson. Introduction to econometrics 3rd ed; 2015.

31. Strauss J. Does better nutrition raise farm productivity? J Polit Econ. 1986;94(2):297-320.

32. Strauss J. The impact of improved nutrition on labor productivity and human resource development: an economic perspective. 1985.
33. Sur M, Senauer B. Nutrition, health, and rural labor productivity: Preliminary wage evidence from Bangladesh. 1999.

34. Thomas D, Strauss J. Health and wages: Evidence on men and women in urban Brazil. J Econ. 1997;77(1):159-85.

35. Tiwasing P, Dawson P, Garrod G. The relationship between micronutrient intake and labor productivity: Evidence from rice-farming households in Thailand. Outlook Agric. 2019;48(1):58-65.

36. Traore N. Does Better Nutritional Status Leas to Higher Farm Productivity?: Theory and Evidence from Rural Mali (Doctoral dissertation, Hunter College, Department of Economics). 2007.

37. Truong Lam Do \& Trung Thanh Nguyen \& Ulrike Grote. Nonfarm employment and household food security: evidence from panel data for rural Cambodia," Food Security: The Science, Sociology and Economics of Food Production and Access to Food, Springer;The International Society for Plant Pathology, 2019; vol. 11(3), 703-718

38. Ulimwengu J, Liverpool-Tasie S, Randriamamonjy J, Ramadan R. Understanding the linkage between agricultural productivity and nutrient consumption: Evidence from Uganda. International Food Policy Research Institute (IFPRI); 2011.

39. Vhurumuku E. Food security indicators. In workshop on integrating nutrition and food security programming for emergency response: Food and Agriculture Organization (FAO). Kenya: Nairobi 2014.

40. Weinberger K. Micronutrient intake and labor productivity: Evidence from a consumption and income survey among Indian agricultural laborers. Outlook Agric. 2004;33(4):255-60.

41. World Food Program. Food Consumption Analysis: Calculation and Use of the Food Consumption Score in Food Security Analysis. Vulnerability and Mapping Branch (ODAV), Rome, Italy 2006.

42. Murthy KV. Arguing a case for Cobb-Douglas production function. Review of Commerce Studies. 2002;20:21.

43. Boisvert RN. The translog production function: its properties, its several interpretations, and estimation problems; 1982.

\section{Publisher's Note}

Springer Nature remains neutral with regard to jurisdictional claims in published maps and institutional affiliations.
Ready to submit your research? Choose BMC and benefit from:

- fast, convenient online submission

- thorough peer review by experienced researchers in your field

- rapid publication on acceptance

- support for research data, including large and complex data types

- gold Open Access which fosters wider collaboration and increased citations

- maximum visibility for your research: over $100 \mathrm{M}$ website views per year

At BMC, research is always in progress.

Learn more biomedcentral.com/submissions 